\title{
The Water Cycle
}

Instructions

1. Choose a starting location and record it on the table on the next page.

2. Role the paper dice to determine which station you move to for the next turn.

\section{Groundwater}

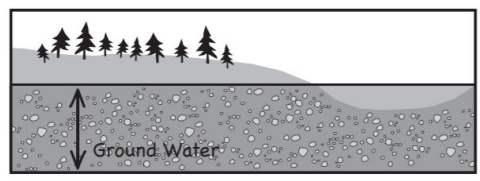

Animal

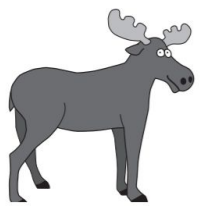

Lake

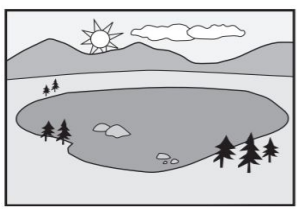

Atmosphere

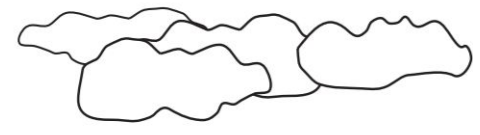

Glacier

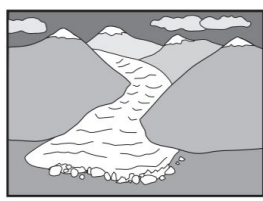

Soil Surface

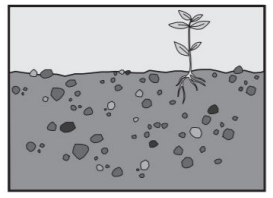

Plant
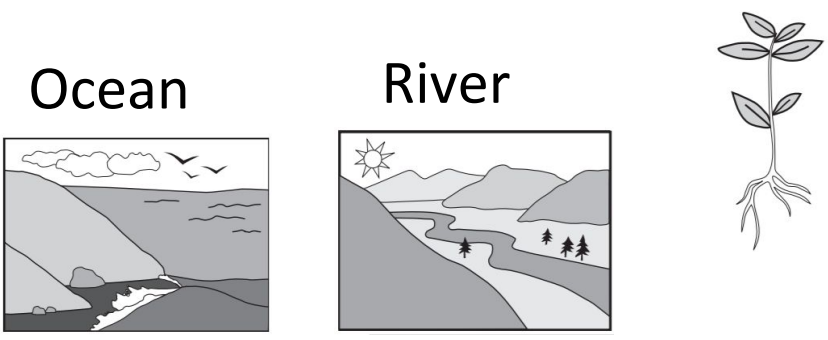

The top row is your location for the turn. The lower rows are the locations where you can move to based on the role of the dice.

\begin{tabular}{|l|l|l|l|l|l|l|l|l|l|}
\hline Roll & $\begin{array}{l}\text { Soil } \\
\text { Surface }\end{array}$ & Plant & River & $\begin{array}{l}\text { Atmos- } \\
\text { phere }\end{array}$ & Ocean & Lake & Animal & $\begin{array}{l}\text { Ground } \\
\text { Water }\end{array}$ & Glacier \\
\hline 1 & Plant & $\begin{array}{l}\text { Atmo- } \\
\text { sphere }\end{array}$ & $\begin{array}{l}\text { Atmos- } \\
\text { phere }\end{array}$ & $\begin{array}{l}\text { Atmos- } \\
\text { phere }\end{array}$ & $\begin{array}{l}\text { Atmo- } \\
\text { sphere }\end{array}$ & $\begin{array}{l}\text { Ground } \\
\text { water }\end{array}$ & $\begin{array}{l}\text { Atmos- } \\
\text { phere }\end{array}$ & River & Glacier \\
\hline 2 & River & $\begin{array}{l}\text { Atmo- } \\
\text { sphere }\end{array}$ & River & Glacier & $\begin{array}{l}\text { Atmo- } \\
\text { sphere }\end{array}$ & $\begin{array}{l}\text { Atmos- } \\
\text { phere }\end{array}$ & $\begin{array}{l}\text { Atmos- } \\
\text { phere }\end{array}$ & Lake & Glacier \\
\hline 3 & $\begin{array}{l}\text { Ground } \\
\text { water }\end{array}$ & $\begin{array}{l}\text { Atmo- } \\
\text { sphere }\end{array}$ & Lake & Lake & Ocean & Animal & $\begin{array}{l}\text { Atmos- } \\
\text { phere }\end{array}$ & Lake & Glacier \\
\hline 4 & $\begin{array}{l}\text { Atmos- } \\
\text { phere }\end{array}$ & $\begin{array}{l}\text { Atmo- } \\
\text { sphere }\end{array}$ & $\begin{array}{l}\text { Ground } \\
\text { water }\end{array}$ & $\begin{array}{l}\text { Soil } \\
\text { surface }\end{array}$ & Ocean & River & $\begin{array}{l}\text { Animal } \\
\text { Ground } \\
\text { water }\end{array}$ & $\begin{array}{l}\text { Ground } \\
\text { water }\end{array}$ \\
\hline 5 & $\begin{array}{l}\text { Soil } \\
\text { surface }\end{array}$ & Plant & Ocean & Ocean & Ocean & Lake & $\begin{array}{l}\text { Soil } \\
\text { surface }\end{array}$ & $\begin{array}{l}\text { Ground } \\
\text { water }\end{array}$ & $\begin{array}{l}\text { Atmosp- } \\
\text { here }\end{array}$ \\
\hline 6 & $\begin{array}{l}\text { Soil } \\
\text { surface }\end{array}$ & Plant & Animal & River & Ocean & Lake & $\begin{array}{l}\text { Soil } \\
\text { surface }\end{array}$ & $\begin{array}{l}\text { Ground } \\
\text { water }\end{array}$ & River \\
\hline
\end{tabular}




\section{The Water Cycle}

Name:

Part I: Choose your starting location and record your movement through the cycle as a water molecule using the table below.

\begin{tabular}{l|l}
\multicolumn{2}{c}{ Station } \\
\hline Start & \\
\hline 2 & \\
\hline 3 & \\
\hline 4 & \\
\hline 5 & \\
\hline 6 & \\
\hline 7 & \\
\hline 8 & \\
\hline 9 & \\
\hline 10 & \\
\hline
\end{tabular}

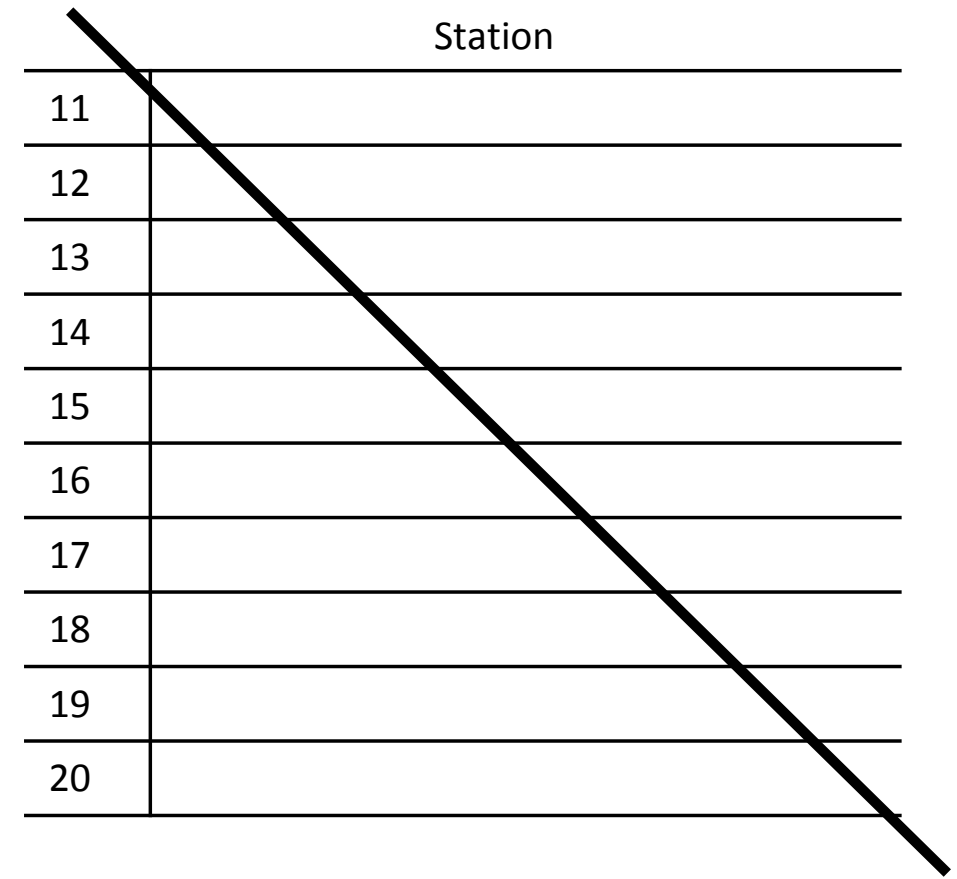

Part II: Make a bar graph of showing how many turns you spent at each station. Label the $Y$ axis clearly.

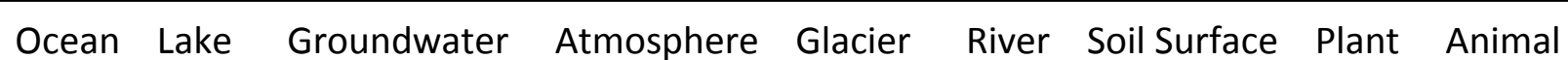

Part III: Where did you spend the most turns? Where did you spend the least turns? Why might that be the case? 